\title{
Agôn
}

Revue des arts de la scène

Critiques | Saison 2013-2014

\section{Exhibit B, conception et mise en scène de Brett Bailey}

La preuve par les corps

\section{Caroline Châtelet}

\section{OpenEdition}

Journals

Édition électronique

URL : http://journals.openedition.org/agon/2709

DOI : 10.4000/agon.2709

ISSN : 1961-8581

Éditeur

Association Agôn

Référence électronique

Caroline Châtelet, "Exhibit B, conception et mise en scène de Brett Bailey », Agôn [En ligne], Critiques, mis en ligne le 22 août 2013, consulté le 23 septembre 2020. URL : http://journals.openedition.org/ agon/2709; DOI : https://doi.org/10.4000/agon.2709

Ce document a été généré automatiquement le 23 septembre 2020.

Association Agôn et les auteurs des articles 


\title{
Exhibit B, conception et mise en scène de Brett Bailey
}

\author{
La preuve par les corps
}

Caroline Châtelet

\section{RÉFÉRENCE}

Exhibit B - conception et mise en scène Brett Bailey

- Église des Célestins, Festival In d'Avignon, du 12 au 23 juillet 2013 - www.festivalavignon.com

- Exhibit B sera présenté au 104, à Paris, du 25 au 27 novembre 2013. www.104.fr

- Exhibit C sera présenté au Cap, à Londres, Edimbourg, Lisbonne, Minde et Rome en 2014.

1 «Exhibit B est une exposition, pas un spectacle théâtral. Prenez votre temps devant chaque installation. Ne vous sentez pas pressé par les personnes derrière vous. " Situé dans le sas précédent l'entrée, cet écriteau à l'adresse des visiteurs signale d'emblée le caractère particulier de l'œuvre à venir. Car oui, Exhibit $B$, installation en série (la précédente s'intitulant Exhibit $A$ et la prochaine, « $C »)$ de l'auteur, metteur en scène et scénographe sud-africain Brett Bailey n'est pas un spectacle. Et la précision ne renvoie ici pas tant à la manifestation dans laquelle l'œuvre s'inscrit - le festival d'Avignon - qu'au rapport étrange noué entre les «installations » et les spectateurs. Réunis dans un sas, ceux-ci reçoivent les consignes d'usage et d'autres, plus étonnantes, l'ensemble de ce protocole ne cessant d'énoncer un caractère solennel. Ainsi, il est demandé à chacun de garder le silence dans l'église et avant d'être lieu de monstration, cet espace conserve son caractère religieux et sacré, renvoyant au caractère inhabituel de ce qui y est exposé. Car si l'« ensemble d'œuvres qui se concentre sur l'histoire coloniale de divers pays européens " d'Exhibit $B$ [cf. programme de salle de l'exposition], utilise tous les codes de la muséographie - cimaises, cartels, éclairages spécifiques, gardiens d'exposition -, toutes ont pour objet central des personnes d'origine africaine. Des humains en chair et en os. Face à cela 
naît un premier choc, découvrir ses congénères dans un dispositif où ils ne maîtrisent pas le temps de leur propre présentation et se donnent comme des œuvres devant lesquelles on peut passer, repasser, revenir librement, ayant quelque chose de profondément déroutant. À la stupeur initiale s'ajoute l'émotion immense et le saisissement profond, violent, nés des installations, chacune renvoyant à un épisode ou un cas précis de l'histoire ancienne et contemporaine de la colonisation, de la domination, de l'extermination et de l'exploitation des populations nord-africaines par les européens. Ces sentiments sont amplifiés à la lecture des cartels : «trophées ramenés en Europe du Congo français. Techniques mixtes: cartes, divers trophées, tête d'antilope, deux pygmées (artefacts culturels), vitrines, accessoires anthropologiques, spectateur(s)» (on voit là aussi que le spectateur est nécessaire à l'aboutissement de l'œuvre, les pièces n'existant que pour être montrées et vues). Montrer / voir / exposer / regarder (ou pas) : toutes ces problématiques posées par Exhibit $B$ s'incarnent directement dans le regard des « interprètes », qui, parfaitement immobiles, observent chaque spectateur, suivant des yeux le moindre de ses déplacements. Passées la première déflagration face aux "preuves » exhibées - «dans (...) un procès pénal, un exhibit (pièce à conviction) est une preuve matérielle ou documentaire portée devant le jury» [cf. programme de salle] - autre chose se fait jour. Parallèlement à la violence de l'histoire abordée répond la beauté formelle de l'ensemble - cohérence de chaque "œuvre ", minutieusement élaborée et savamment réparties dans cette église en chantier - ainsi qu'une permanente mise à distance, suscitée par le ton froid, clinique et grinçant des cartels - Objet trouvé désignant, par exemple, un réfugié $\mathrm{du} \mathrm{XXI}^{\mathrm{e}}$ siècle en attente d'expulsion. Ce croisement entre réalité historique, ironie caustique, brin de cynisme et maîtrise esthétique indubitable, tout en rendant supportable et singulièrement juste l'exposition - pas de pathos ni de moralisme - agit comme amplificateur du propos. Et si Exhibit B nous dit, aussi, que la violence faite aux étrangers n'a pas disparu, bien au contraire, elle le fait sans nier la complexité de ces problématiques ni laisser de côté la question de la forme artistique.

2 Ce geste sur le fil trouve l'une de ses plus ambiguës expressions devant le Cabinet de curiosités du Docteur Fischer, où un chœur namibien "décapité" - seules les têtes dépassent des cimaises - livre des chants à l'expressivité et à l'interprétation saisissantes. Seule pièce devant laquelle le spectateur peut s'asseoir, celle-ci rend possible un éventuel apaisement, sans atténuer la sauvagerie des sévices exposés. Ce n'est que dans l'addendum de l'exposition que la simplification apparaît: dans le sas final, sont adjointes aux biographies des participants leur motivation personnelle à participer à ce projet. Si ces éléments permettent de saisir le souci de mêler à l'équipe artistique des amateurs, ces prises de paroles tendent souvent à écraser le propos par des appels à la pédagogie ou au didactisme parfois moralisateur. Preuve que la force d'une œuvre dépasse bien souvent l'ambition de l'intention individuelle de l'interprète... 
Exhibit B

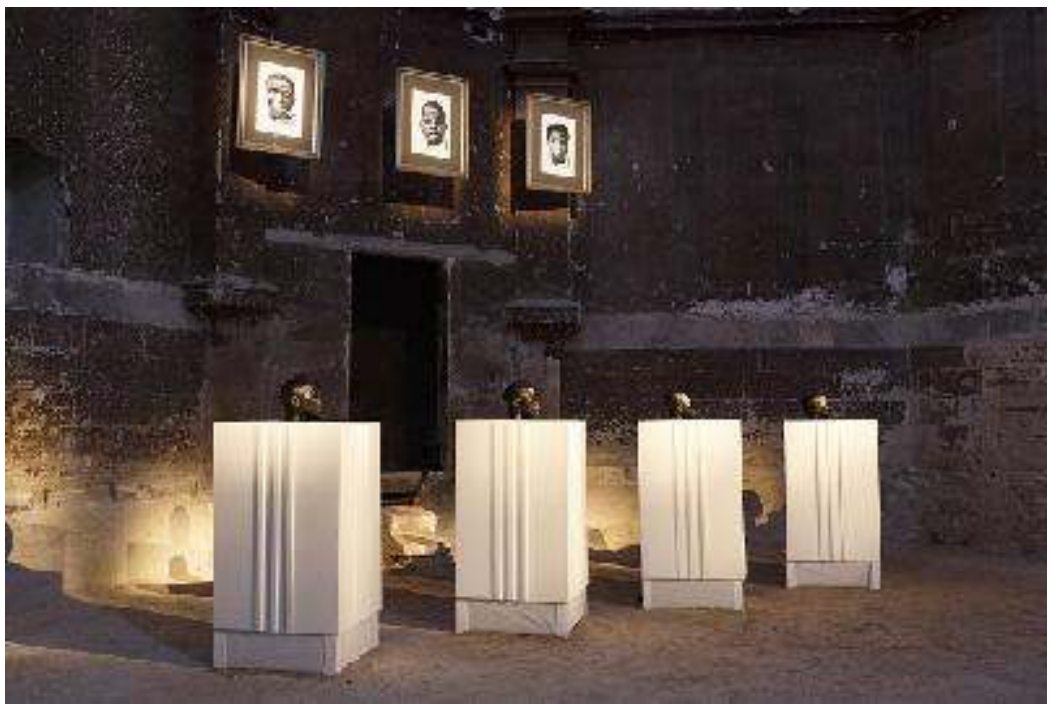

() Christophe Raynaud de Lage / Festival d'Avignon 